\title{
TO COMPARE THE EFFICACY OF ONCE A DAY VERSUS TWICE DAILY APPLICATION OF AMOROLFINE 0.25\% CREAM- A SINGLE-BLINDED, RANDOMIZED, CONTROL STUDY
}

\author{
Nitin Lade', Neha Pathrabe2, Pallavi Morey3 \\ ${ }^{1}$ Ex. Associate Professor, Department of Dermatology, JNMC, Wardha. \\ ${ }^{2}$ Resident, Department of Dermatology, JNMC, Wardha. \\ ${ }^{3}$ Consultant Dermatologist, Nagpur.
}

\begin{tabular}{l}
\hline ABSTRACT \\
BACKGROUND \\
maperficial dermatophytosis is a common clinical entity in tropical countries like India. Limited tinea corporis and cruris can be \\
Aim- To compare the efficacy of once a day versus twice daily application of amorolfine $0.25 \% \mathrm{cream}$.
\end{tabular}

\section{MATERIALS AND METHODS}

All new patients having limited tinea corporis and tinea cruris with $\mathrm{KOH}$ positivity were recruited in the study. Patients were randomly grouped as once a day application (Group A) and twice a day application (Group B). Study duration was 6 weeks, first visit after 3 weeks (end of the treatment phase) and second visit after 6 weeks (end of followup). During each visit, patients were examined, asked about the side effects, global response was noted, $\mathrm{KOH}$ scraping and clinical photographs were taken.

\section{RESULTS}

A total of 82 patients were recruited in the study, 12 patients lost to followup. Sixty patients completed the study, 30 in each group. Demographics were comparable in each group. At the end of the study, $80 \%$ patients in group A and $90 \%$ in group B got total clearance which was not significant.

\section{CONCLUSION}

Twice a day application of amorolfine is more effective than once a day.

\section{KEYWORDS}

Amorolfine, Limited, Tinea Corporis, Tinea Cruris.

HOW TO CITE THIS ARTICLE: Lade N, Pathrabe N, Morey P. To compare the efficacy of once a day versus twice daily application of amorolfine 0.25\% cream- A single-blinded, randomized, control study. J. Evolution Med. Dent. Sci. 2017;6(89):6258-6260, DOI: $10.14260 /$ jemds $/ 2017 / 1360$

\section{BACKGROUND}

Dermatophytosis is superficial fungal infection of skin, hair and nail. It is caused by dermatophytes which are filamentous fungi. It has affinity for keratin, hence it invades and multiplies in skin and its appendages causing infection.[1] Dermatophytes have been divided into three subgroups: Trichophyton (infects skin, hair and nail), Epidermophyton (infects skin and nail), Microsporum (infects skin and hair). Ringworm or dermatophytic infections are common health problem. World Health Organization stated that 20\% of people are suffering from cutaneous fungal infections worldwide.[2] Dermatophytosis is more rampant in overcrowded areas, poor hygienic condition, low standard of living and high humidity. Tinea corporis and Tinea cruris are the most common clinical types of dermatophytosis. [3]

Topical or oral antifungals are used in management of dermatophytes. Topical therapy is effective for limited cutaneous infection.

'Financial or Other Competing Interest': None.

Submission 06-10-2017, Peer Review 01-11-2017,

Acceptance 07-11-2017, Published 13-11-2017.

Corresponding Author:

Dr. Nitin Lade,

Pratap Nagar,

Nagpur.

E-mail:dr.nitin06@rediffmail.com

DOI: $10.14260 /$ jemds $/ 2017 / 1360$

\section{(c) $(i)$}

In recent times new extended-spectrum triazoles and allylamines, morpholine derivative have been introduced. Some of the newer agents require only once daily application and shorter courses of treatment, and are associated with lower relapse rates.[4] Amorolfine is a phenylmorpholine derivative, having high activity against yeast and dermatophytes.[5] It has fungistatic action by inhibiting ergosterol biosynthesis.[6] Amorolfine once a daily application has been recommended. Very few studies are available on Amorolfine. ${ }^{[7],[8]}$ In this study, we are comparing the efficacy and tolerance of amorolfine, once a day versus twice a day application.

\section{Aims and objectives}

To compare the efficacy of once a day versus twice daily application of amorolfine $0.25 \%$ cream.

\section{MATERIALS AND METHODS}

Study Design in

A single-blinded, randomized, control, pilot study.

All newly diagnosed patients, above 16 years of age having tinea corporis and tinea cruris with limited skin lesions $<5$ patches and $<5 \mathrm{~cm}$ in size, with positive $\mathrm{KOH}$ skin scraping, who came to Dermatology OPD of Jawaharlal Nehru Medical College, were enrolled in the study. Patients had extensive lesions, negative $\mathrm{KOH}$ scraping, immunesuppressive disease or drugs, pregnant and lactating female 
patients were excluded. Patients were clearly explained of the nature of study and written consent was taken for the participation in the study

Detailed history including age, sex, occupation, duration of disease, personal and past history were taken. Detailed cutaneous examination and skin scraping for $\mathrm{KOH}$ mount from the advancing border of the lesion was taken during each visit along with clinical photographs. Computer-based random allocation was done into two groups: Group A, subjected to once a day application of amorolfine $0.25 \%$ cream and Group B, twice daily application of amorolfine $0.25 \%$ cream. In both the groups, period of application of the drug was 3 weeks. The instruction was given to apply the thin layer of cream on the lesions and surrounding $1 \mathrm{~cm}$ area of lesion/s. Each patient had three visits, 1 st when treatment was given, $2^{\text {nd }}$ after completion of 3 weeks of treatment period, and 3 rd i.e. followup period of 3 weeks after completion of treatment. Global response was scored as follows: a) Healed (100\% cleared), with $\mathrm{KOH}$ negative; b) Excellent response with $\mathrm{KOH}$ negative (90 - 99\% cleared); c) good response ( 25 to $89 \%$ cleared) with $\mathrm{KOH}$ positive; d) Fair or no response (0 to $25 \%$ cleared), mycology positive.

Data obtained were analysed by using Chi-square test, SPSS 20.0 version. As this was a pilot study, sample size 30 in each group was taken.

\section{RESULTS}

Total 72 patients were enrolled for this study, 37 patients in Group A and 35 patients in Group B. But 7 patients of Group A and 5 patients of Group B were lost to followup. Therefore, the sample size was of 60 patients with 30 patients in each group. The duration of disease ranges from 2 weeks to 6 weeks.

Twenty two males and 8 females were in group A, while 19 males and 11 females were in group B. Age distribution shown in Table 1 , mean age in group $A$ was 36.37 years, and 37.26 years in group B. In sixty patients, $14(23 \%)$ were having tinea cruris and 46 (77\%) having corporis. Six (20\%) patients of Tinea cruris were in group A and $8(27 \%)$ in group B, $24(80 \%)$ patients of Tinea corporis were in group A and $22(73 \%)$ in group B. Global assessment of the patients in Group A and Group B is shown in Table 2. In group A, 19 $(63 \%)$ patients, and in group B, $24(80 \%)$ had total clearance which increased to $77 \%$ and $87 \%$ respectively at last followup ( $3^{\text {rd }}$ visit), which was not significant. Excellent response also follows the same trend, as shown in Table 2, which was again non-significant. Clinical and mycological clearance at last followup (3rd visit) is shown in Table 3. Only one patient in each group complained of mild irritation. There was no recurrence in followup period.

\begin{tabular}{|c|c|c|c|c|}
\hline \multirow{2}{*}{$\begin{array}{l}\text { Range of Age } \\
\text { Group (Years) }\end{array}$} & \multicolumn{2}{|c|}{ Group A } & \multicolumn{2}{|c|}{ Group B } \\
\hline & $\begin{array}{c}\text { No. of } \\
\text { Patients }\end{array}$ & $\%$ & $\begin{array}{c}\text { No. of } \\
\text { Patients }\end{array}$ & $\%$ \\
\hline $11-20$ & 4 & $13.33 \%$ & 4 & $13.33 \%$ \\
\hline $21-30$ & 5 & $16.67 \%$ & 7 & $23.33 \%$ \\
\hline $31-40$ & 9 & $30 \%$ & 6 & $20 \%$ \\
\hline $41-50$ & 9 & $30 \%$ & 7 & $23.33 \%$ \\
\hline $51-60$ & 3 & $10 \%$ & 5 & $16.67 \%$ \\
\hline Total & 30 & $100 \%$ & 30 & $100 \%$ \\
\hline Mean \pm SD & \multicolumn{2}{|c|}{$36.37 \pm 12.35$} & \multicolumn{2}{|c|}{$37.27 \pm 12.23$} \\
\hline
\end{tabular}

\begin{tabular}{|c|c|c|c|c|c|c|}
\hline \multirow{2}{*}{$\begin{array}{c}\text { Parameter } \\
\text { Lesion/s Cleared in \% }\end{array}$} & \multicolumn{3}{|c|}{ End of the Treatment (2nd visit) } & \multicolumn{3}{|c|}{3 Weeks Post-Treatment (3rd visit) } \\
\hline & $\begin{array}{c}\text { Group A } \\
\mathbf{n}=\mathbf{3 0}\end{array}$ & $\begin{array}{c}\text { Group B } \\
n=30\end{array}$ & $P$ value & $\begin{array}{c}\text { Group A } \\
\mathbf{n}=\mathbf{3 0}\end{array}$ & $\begin{array}{c}\text { Group B } \\
\mathbf{n}=\mathbf{3 0}\end{array}$ & $P$ value \\
\hline Totally cleared with negative mycology $(100 \%)$ & $19(63.33 \%)$ & $24(80 \%)$ & $>0.05$ & $23(76.67 \%)$ & $26(87 \%)$ & $>0.05$ \\
\hline $\begin{array}{l}\text { Excellent improvement with negative mycology } \\
\qquad \text { (90 to } 99 \% \text { ) }\end{array}$ & $5(16.67 \%)$ & $3(10 \%)$ & $>0.05$ & $1(3.33 \%)$ & $1(3.33 \%)$ & $>0.05$ \\
\hline $\begin{array}{l}\text { Good improvement with positive mycology } \\
\text { (25 to } 89 \% \text { ) }\end{array}$ & $4(13.33 \%)$ & $1(3.33 \%)$ & $>0.05$ & $3(10 \%)$ & $1(3.33 \%)$ & $>0.05$ \\
\hline $\begin{array}{c}\text { Fair improvement or no change/improvement } \\
\text { with residual lesions ( } 0 \text { to } 24 \% \text { ) }\end{array}$ & $2(6.67 \%)$ & $2(6.67 \%)$ & $>0.05$ & $3(10 \%)$ & $2(6.67 \%)$ & $>0.05$ \\
\hline
\end{tabular}

Table 2. Global Assessment of the Patients

\begin{tabular}{|c|c|c|c|}
\hline Clearance & Group A & Group B & P Value \\
\hline Complete & $24(80 \%)$ & $27(90 \%)$ & \multirow{2}{*}{$>0.05$} \\
\cline { 1 - 3 } Incomplete & $6(20 \%)$ & $3(10 \%)$ & \\
\hline \multicolumn{2}{|r|}{ Table 3. Clearance Rate at Last Visit } \\
\hline
\end{tabular}

\section{Once Daily Application of Amorolfine}

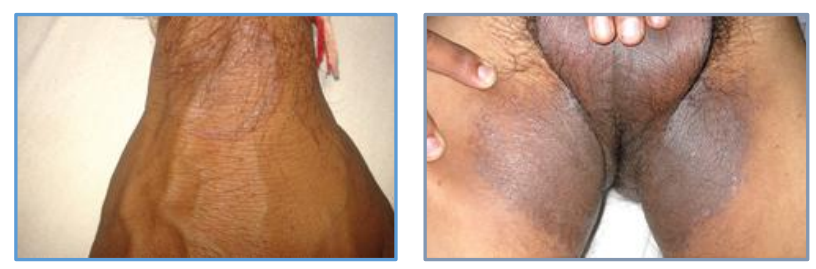

First Visit (Before Treatment)

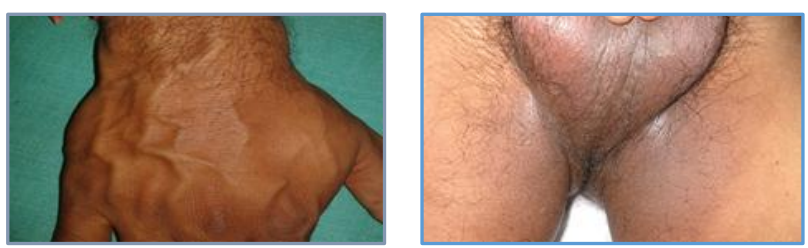

Second visit (At the End of treatment)

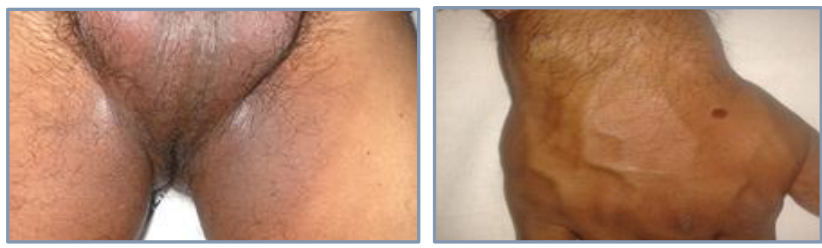

Third Visit (Three Weeks of Post-treatment)

Twice Daily Application of Amorolfine 

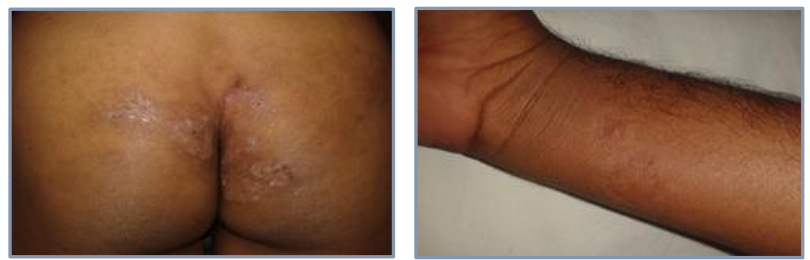

First Visit (Before Treatment)
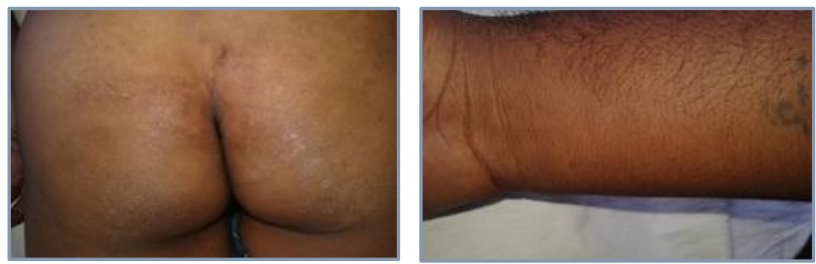

Second Visit (At the End of Treatment)
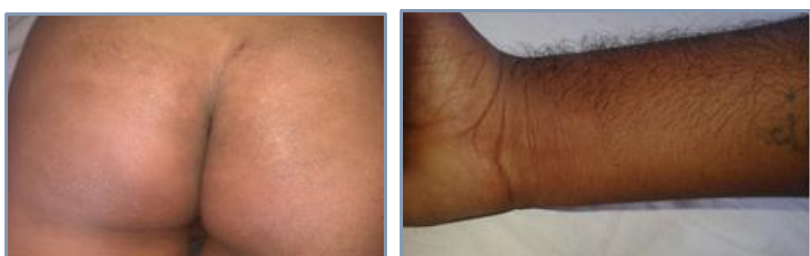

Third Visit (Three Weeks of Post-treatment)

\section{DISCUSSION}

Amorolfine, a morpholine derivative, initially was exclusively used as nail lacquer for onychomycosis. In recent years, it is being using in cream formulation in the management of dermatophytosis.

In the present study, total 60 patients completed the study, 30 in each group. The dermatophytic infection mostly seen in younger age group 18 to 40 years, with mean age 37 years. The present study and other studies have noted that dermatophytosis is mostly the disease of younger age. $[9,10]$ Males were more affected than females, i.e. group A 22 (73.33\%) and Group B 19 (63.33\%), which may be due to outdoor working conditions. In the present study, tinea corporis was diagnosed in 24 (80\%) and 22 (73.33\%) patients in Group A and Group B respectively. This indicates tinea corporis was more common than tinea cruris. Current study and most of the other studies had similar observation, which overall noted that dermatophytosis infects young population, males outnumber females, and tinea corporis is more common than cruris. $[9,10,11,12]$

Global assessment of patients in Table 2 indicates response rate was more in group $B$ from beginning to end. After 6 weeks ( $3^{\text {rd }}$ visit), clinical and mycological cure was 24 (80\%) patients in group A, while it was 26 (86.67\%) in Group B. Present study pointed that twice daily application of amorolfine clears the infection rapidly than once application. But overall efficacy was nearly the same in both the groups at the end of study, perhaps compliance was better in group A Even though Group B had the higher clearance rate than Group A, but it was not statistically significant ( $p$ value > 0.05). Mild irritation was reported in one patient each in both the groups. Amorolfine with once a day application had clearance rate of $76 \%$ to $83 \%$, which is comparable with group A, but twice a day application has upper hand. $[7,8,13,14]$ Topical Amorolfine is recommended for once daily application for $2-3$ weeks. This study is first of its kind to find whether twice daily application has any additional benefit over once daily application in tinea cruris and corporis.

\section{CONCLUSION}

Twice a day application of amorolfine is more effective than once a day.

\section{REFERENCES}

[1] Weitzman I, Summerbell RC. The dermatophytes. Clin Microbiol Rev 1995;8(2):240-59.

[2] Marques SA, Robles AM, Tortorano AM, et al. Mycoses associated with AIDS in the third world. Med Mycol 2000;38(Suppl 1):269-79.

[3] Singh S, Beena PM. Profile of dermatophyte infections in Baroda. Indian J Dermatol Venereol Leprol 2003;69(4):281-3.

[4] Del Palacio A, Cuetara S, Noriega AR. Topical treatment of tinea corporis and cruris with eberconazole (WAS 2160) cream $1 \%$ and 2\%: a phase II dose finding pilot study. Mycoses 1995;38(7-8):317-24.

[5] Polak A. Antifungal activity in vitro of R0-144767/002, a phenylpropyl-morpholine. Sabouraudia 1983;21(3):205-13.

[6] Polak-Wyss A, Lengsfeld H, Oesteshelt G. Effect of oxiconazole and Ro 14-4767/002 on sterol pattern in Candida albicans. Sabouraudia 1985;23(6):433-41.

[7] Del Palacio A, Lopez S, Gimeno C, et al. Experience with amorolfine in the treatment of dermatomycoses. Dermatology 1992;184:25-9.

[8] Del Palacio A, Lopez S, Gimeno C, et al. Randomized comparative study: amorolfine cream $(0.125 \%, 0.25 \%$ and $0.5 \%$ ) in dermatomycoses. J Dermatol Treatment 1991;1:299-303.

[9] Thaker SJ, Mehta DS, Shah HA, et al. A comparative randomized open label study to evaluate efficacy, safety and cost effectiveness between topical $2 \%$ sertaconazole and topical $1 \%$ butenafine in tinea infections of skin. Indian J Dermatol 2013;58(6):451-6.

[10] Jerajani H, Janaki C, Kumar S, et al. Comparative assessment of the efficacy and safety of sertaconazole $(2 \%)$ cream versus terbinafine cream $(1 \%)$ versus luliconazole $(1 \%)$ cream in patients with dermatophytoses: a pilot study. Indian J Dermatol 2013;58(1):34-8.

[11] Bhagra S, Ganju SA, Kanga A, et al. Mycological pattern of dermatophytosis in and around Shimla hills. Indian J Dermatol 2014;59(3):268-70.

[12] Surendran KAK, Bhat RM, Boloor R, et al. A clinical and mycological study of dermatophytic infections. Indian J Dermatol 2014;59(3):262-7.

[13] Selvan TA, Gutha G, Vijaybhaskar, et al. Comparative evaluation of newer topical antifungal agents in the treatment of superficial fungal infection (Tinea or Dermatophytic). International Research Journal of Pharmacy 2013;4(6):224-8.

[14] Banerjee M, Ghosh AM, Basak S, et al. Comparative evaluation of effectivity and safety of topical amorolfine and clotrimazole in the treatment of tinea corporis. Indian J Dermatol 2011;56(6):657-62. 